\title{
Rising temperatures advance the main flight period of Bombus bumblebees in agricultural landscapes of the Central European Plain
}

\author{
Tadeusz Pawlikowski ${ }^{1}$, Tim H. Sparks ${ }^{2,3}$, Piotr Olszewski ${ }^{4}$, Krzysztof Pawlikowski ${ }^{5}$, \\ Lucjan RuTKOWSKI $^{6}$, Rafał JAKUBOWSKI ${ }^{7}$ \\ ${ }^{1}$ Institute of Ecology and Environmental Protection, Copernicus University, Lwowska 1, 87-100, Toruń, Poland \\ ${ }^{2}$ Institute of Zoology, Poznań University of Life Sciences, Wojska Polskiego 71c, 60-625, Poznań, Poland \\ ${ }^{3}$ Museum of Zoology, University of Cambridge, Downing Street, Cambridge CB2 3EJ, UK \\ ${ }^{4}$ Department of Ecology and Biogeography, Copernicus University, Lwowska 1, 87-100, Torun, Poland \\ ${ }^{5}$ National Marine Fisheries Research Institute, Department of Fisheries Oceanography and Marine Ecology, Kołłąaja 1, \\ 81-332, Gdynia, Poland \\ ${ }^{6}$ Chair of Geobotany and Landscape Planning, Copernicus University, Lwowska 1, 87-100, Toruń, Poland \\ ${ }^{7}$ Centre of New Technologies, University of Warsaw, Banacha 2c, 02-097, Warsaw, Poland
}

Received 25 July 2019 - Revised 11 January 2020 - Accepted 20 February 2020

\begin{abstract}
This study examined shifts over a 35-year period in the phenology of the four most important bumblebee species (Bombus terrestris, B. lapidarius, B. pascuorum and B. hortorum) in Central Europe. The species showed similar temporal trends, significantly advancing components of their main flight period in association with rising temperatures such that, for example, mid-dates of the main flight period advanced by 10-23 days over the study period. Drivers of this change differed between the four species. Trends in, and drivers of, the timing of first queens, first workers and first males were less consistent. Aspects of the phenology of the least common species, $B$. hortorum, were up to a month earlier than the other species and climatic effects less clear cut. There were some suggestions of differences between species trends. These results stress the importance of considering changes and drivers of change for the Bombus family on a species-specific basis with the need to pay more attention to the life history traits of the study organisms.
\end{abstract}

bumblebee / Bombus / climate / agriculture / phenology

\section{INTRODUCTION}

Recent climate changes have influenced many living organisms, including the phenology, population size and migration and distribution patterns of insects (e.g. Warren et al. 2001; Bale et al. 2002; Konvicka et al. 2003; Dell

Corresponding author: T. Sparks, thsparks@btopenworld.com Manuscript editor: James Nieh et al. 2005; Sparks et al. 2007; Rasmont et al. 2015). This is likely to be both an indirect effect, because local trends in temperatures affect plants, which as the main food source of many phytophagous insects influence their activity, and a direct effect, since increasing temperature affects insect metabolism and activity per se. Effects have also been detected on species of a general economic and ecological importance (Gordo and Sanz 2006; Harrington et al. 2007; Le Conte and Navajas 2008). Among potentially interesting species are 
bumblebees, effective pollinators which occupy both rural and urban habitats. When foraging, they visit flowers of various plant species, especially of Labiatae, Leguminosae and Asteraceae (Pawlikowski et al. 2008; Goulson 2010). Various studies have indicated that the timing of bumblebee queen emergence in spring is triggered by soil or air temperature thresholds (e.g. Alford 1969; Goodwin 1995; Kudo and Cooper 2019).

In our study area in central Poland, the four study species Bombus terrestris (Linnaeus), $B$. lapidarius (Linnaeus), B. pascuorum (Scopoli) and B. hortorum (Linnaeus) are common and of special interest, although $B$. hortorum is less numerous than the other three. During the study period (1981-2015), these four species accounted for $85-90 \%$ of all Bombus specimens recorded. B. terrestris is native to the Palaearctic region: Europe, North Africa and temperate regions of Asia. In 2013, it first crossed into the Arctic Circle. It was deliberately introduced to New Zealand in the late 1800s and, as a result of escapes from use as a commercial pollinator, has also been established in Australasia and South America. B. lapidarius is native to the Palaearctic region and has also been introduced elsewhere, cf. B. terrestris . B. pascuorum is native to the West Palaearctic, and B. hortorum is native to the Palaearctic (Williams 2000; Velthuis 2002; Rasmont et al. 2008; Martinet et al. 2015).

The bumblebee life cycle is completed in 1 year. An overwintering queen builds a nest and rears the first workers. The growing colony will produce males and some new queens. After mating, the fertilised new queens seek a place to hibernate whilst the original colony including the old queen collapses. Bumblebee nests are usually above ground in rodent nests, hollow trees, walls of houses, thatched roofs, barns, attics and bird nest boxes. However, nests of $B$. terrestris and $B$. lapidarius are usually subterranean and larger than other species (to 1000 individuals) (Biliński 1997; Alford 2011). Bumblebees are large, active bees but are not aggressive. Their natural enemies are the birds Merops apiaster Linnaeus and Pernis apivorus (Linnaeus) and the mammals Ursus arctos Linnaeus and Vulpes vulpes (Linnaeus).
Bumblebees provide a range of potential economic benefits. Most importantly to man, they pollinate a large number of flowering plants, including different cultures of wild strawberries, strawberries, blueberries, tomatoes, Capsicum spp., fruit trees and shrubs.

As noted above, the spring emergence timing of queens is likely triggered by air or soil temperature thresholds, thus warmer springs would allow thresholds to be met earlier, resulting in earlier emergence. From studies of other insects, we believe that weather of a few antecedent months will influence this timing. In turn, the timing of queen emergence will likely influence the timing of workers and then of males. Thus, the appearance of these later castes might only be influenced by the date of queen emergence and weather following this event which may slow or accelerate their development rates. The main goals of this paper are to examine for changes to the phenology of four important bumblebee species over a 35-year period and to identify potential links to climatic factors, i.e. temperature and precipitation.

\section{MATERIAL AND METHODS}

\subsection{Study area and bumblebee observations}

Research on bumblebees in the agricultural landscape of the Kujawy region of Poland was conducted in the vicinity of Strzelno $\left(52.6^{\circ} \mathrm{N}\right.$, $\left.18.2^{\circ} \mathrm{E}\right)$ ca. $20 \mathrm{~km}$ south of the town of Inowrocław from April to October in 19812015. During this research, observations, and occasionally captures, of bumblebees were carried out along transects of 4-6 km length running through the study area. Transects were selected to contain typical flowering plants preferred by bumblebees. Bumblebee nests were also observed, especially those of $B$. terrestris, $B$. lapidarius, B. pascuorum and B. hortorum . Visits to the study area were made at 2-3-day intervals during April-May and at 5-day intervals during June-October, between 10:00 and 17:00 local time. Visits were only made during optimal weather conditions for bumblebee flight; i.e. sunny, and air temperature of $15-25^{\circ} \mathrm{C}$. All 
bumblebee individuals were registered along the transects together with a record of their activity, i.e. searching for food plants, flying near nest, mating. Special attention was paid to those parts of the transects (such as roadsides, gardens, orchards and meadows) containing flowering plants of Labiatae, Leguminosae and Asteraceae.

All transects were recorded by the same two people (TP and KP), well trained in bumblebee identification. On the study area, we recorded 13 bumblebee species. The dominant species were $B$. terrestris (35-45\% of all specimens), B. lapidarius (25-35\%), B. pascuorum (25$35 \%$ ) and $B$. hortorum (10-25\%). The other recorded species were B. lucorum (Linnaeus), B. muscorum (Fabricius), B. ruderatus (Linnaeus), B. ruderarius (Muller), B. sylvarum (Linnaeus), B. veteranus (Fabricius), B. bohemicus (Seidl), B. rupestris (Fabricius) and B. vestalis (Fourcroy) which were present at low density (total $<10 \%$ ). More information on the structure of the local bumblebee community is given elsewhere (Pawlikowski 1984, 2008).

Monthly mean temperature and monthly total precipitation were taken from the gridded CRU TS4.03 dataset (Harris et al. 2014) for the rectangle $52.0-53.0^{\circ} \mathrm{N}$ and $18.0-19.0^{\circ} \mathrm{E}$ via the KNMI Climate Explorer Website (http://climexp.knmi.nl).

\subsection{Statistical analysis}

Key dates of bumblebee flight activity for each year were expressed as Julian date/days of the year (days after December 31) and derived for the following: date of first queen observed, date of first worker observed, date of first male observed, beginning and end of the main flight period. The beginning of the main flight period was defined as the date when at least $50 \%$ of the observed bees were workers, the end of the main flight period when the first new queen was observed. Based on these data, the following measures were also derived: duration between first queen and first worker, mid-date of the main flight period, and duration of the main flight period.
Trends in phenology were assessed by regression on year to examine for changes over time. Trends in the climate variables were also tested by regression on year. Differences in means between species for each phenological variable were tested using ANOVA with year and species as two categorical variables. Significant results were followed up by Tukey's HSD tests. Differences between species in their trends over time were evaluated by testing for equality of slopes in a pooled regression, including year as a continuous variable.

Relationships between phenology and climate variables (monthly mean temperatures, monthly total precipitation) and the date of the first queen were examined using stepwise regression (with alpha-to-enter and alpha-toremove both set at 0.10 ). Candidate variables were the date of the first queen (obviously not included for the first queen models) and the temperature and precipitation variables for the three calendar months up to and including the month in which the mean of that phenological event occurred. The only exceptions to this rule were for the date of the first worker and for the duration between first queen and first worker, for which only the months spanning the first queen/first worker mean dates were used. For clarity, candidate variables are identified in later tables. The rationale behind this choice is that only weather in the recent past was considered likely to influence phenology (either directly or indirectly via, for example, flower development), that the timing of the first queen could influence subsequent events, but that the development of workers was likely only to relate to weather since first queen emergence. Differences between species in their response to temperature were evaluated by testing for equality of slopes in a pooled regression.

Sample size differed slightly between variables, because not all information was collected every year. All statistical analyses were conducted using the MINITAB v.18 package with $p=0.05$ used as a threshold for significance testing, but, because of the variable nature of the data, marginal results $(0.05<p<0.10)$ are also discussed. The reader should bear in mind that with such a large number of tested relationships some may have been significant by chance. 


\section{RESULTS}

\subsection{Trends in time}

Significant trends were detected in 15 of the 32 analysed bumblebee variables, and two further variables were marginal. There were no significant trends in the timing of the first queen, first worker and first male bumblebees except for a significant advance in the timing of first $B$. hortorum queen and a significant delay in the timing of first $B$. hortorum worker (Table I). The advancing trend for first $B$. lapidarius worker was not quite significant $(p=0.068)$. The interval between first queen and first worker became significantly shorter for $B$. lapidarius but significantly longer for B. hortorum. Trends in the beginning, end and mid-date of the main flight period were more consistent (Figure 1); all advanced significantly except the beginning and mid-date of the main flight period of $B$. hortorum whose advance was not significant, although the latter was marginal ( $p=0.053$, Table I). Advances in mid-date of the main flight period over the 35-year period was 13 days for $B$. terrestris, 23 days for $B$. lapidarius, 12 days for $B$. pascuorum and 10 days (not significant) for $B$. hortorum. The duration of the main flight period of $B$. terrestris was significantly reduced by about 7 days over the study period (Table I). When assessed in a pooled regression, differences between species in their trends for the interval between the first queen and first worker were significant $\left(F_{3}, 103=6.78\right.$, $p<0.001)$, and differences in trends for first worker $\left(F_{3,103}=2.17, p=0.096\right)$ and for the mid-date of the main flight $\left(F_{3,121}=2.50, p=\right.$ 0.063 ) were marginal. In the case of the first worker, trends in first worker and in the first queen-first worker interval appear different in $B$. hortorum . For the mid-date of the main flight period, the advancing trend for B. lapidarius is greater than for the other species (Table I).

\subsection{Differences in phenology between species}

There were highly significant $(p<0.001)$ species differences in all of the assessed variables (Tables I and II). B. terrestris had a later mean first worker and a longer interval between first queen and first worker. Its main flight period, like that of $B$. lapidarius, was also relatively late whilst that of B. pascuorum was intermediate. $B$. hortorum appeared most different from the other species with later first queens but earlier first males, its main flight period was early but of longer duration.

\subsection{Relationship between phenology and climate variables}

In the 1981-2015 study period there were significant increases in monthly mean temperature in April, June, July, August and November but no significant changes in any monthly precipitation, although that for May was marginal (Table III). For the 32 regression models, the stepwise approach selected temperature variables 24 times, precipitation variables 3 times and first queen dates 10 times (Table IV). For the 24 selected temperature variables, 16 had negative coefficients implying earlier phenology associated with warmer temperatures.

Temperature effects on first timing of castes were mixed. For B. terrestris, B. lapidarius and $B$. pascuorum, increased temperatures were associated with advance in the first appearance of queens, but for $B$. terrestris, there was also a suggestion that warm Aprils could delay the first queen, although with a smaller coefficient than the negative association with March temperature. For dates of first workers, all species were positively influenced by the date of first queens, and for $B$. terrestris and B. hortorum warmer temperatures were then associated with delayed workers. For B. terrestris and B. hortorum results for first males were mixed.

For the main flight period, the effects of temperature were somewhat more consistent (Figure 2), although not necessarily affecting the beginning and end dates (or even species) equally. For $B$. terrestris, the three main flight dates (beginning, end, mid-date) were earlier in years with early flying queens but advances were also associated with increasing summer temperatures. The effect on end date for $B$. terrestris was greater than on the beginning date, such that a reduction in the duration of the main flight period was 
Table I. A summary of trends in the phenology of Bombus in the Kujawy region of Poland during 1981-2015

\begin{tabular}{|c|c|c|c|c|c|c|c|}
\hline Variable & $N$ & Mean date & Mean & SD & Trend & $p$ value & $R^{2}(\%)$ \\
\hline \multicolumn{8}{|l|}{ Bombus terrestris } \\
\hline Date of first queen (FQ) & 34 & 14 April b & 104.0 & 8.78 & 0.013 & 0.932 & $<0.1$ \\
\hline Date of first worker (FW) & 30 & 2 June a & 153.0 & 14.15 & 0.162 & 0.597 & 1.0 \\
\hline Duration: FQ to FW (days) dFW & 30 & - & $48.5 \mathrm{a}$ & 12.33 & 0.011 & 0.966 & $<0.1$ \\
\hline Date of first male (FM) & 30 & 20 July a & 201.0 & 18.97 & -0.230 & 0.574 & 1.1 \\
\hline Beginning of main flight (BMF) & 34 & 7 August a & 219.0 & 5.41 & -0.272 & 0.002 & 26.0 \\
\hline End of main flight (EMF) & 34 & 29 August a & 240.6 & 6.74 & -0.468 & $<0.001$ & 49.5 \\
\hline Main flight: mid-date (MFM) & 34 & 18 August a & 230.1 & 5.75 & -0.363 & $<0.001$ & 40.9 \\
\hline Duration of main flight (days) (dMF) & 34 & - & $21.6 \mathrm{~b}$ & 3.89 & -0.196 & 0.002 & 26.0 \\
\hline \multicolumn{8}{|l|}{ Bombus lapidarius } \\
\hline Date of first queen (FQ) & 34 & 20 April b & 109.7 & 10.49 & 0.099 & 0.588 & 0.9 \\
\hline Date of first worker (FW) & 30 & 17 May b & 137.3 & 12.03 & -0.462 & 0.068 & 11.4 \\
\hline Duration: FQ to FW (days) dFW & 30 & - & $28.2 b$ & 8.34 & -0.478 & 0.004 & 25.5 \\
\hline Date of first male (FM) & 30 & 13 July a & 194.2 & 10.60 & -0.184 & 0.420 & 2.3 \\
\hline Beginning of main flight (BMF) & 33 & 6 August a & 218.2 & 9.51 & -0.639 & $<0.001$ & 44.9 \\
\hline End of main flight (EMF) & 33 & 22 August $b$ & 233.7 & 7.61 & -0.663 & $<0.001$ & 75.5 \\
\hline Main flight: mid-date (MFM) & 33 & 14 August $b$ & 226.2 & 8.13 & -0.658 & $<0.001$ & 65.3 \\
\hline Duration of main flight (days) (dMF) & 33 & - & $15.5 \mathrm{c}$ & 6.20 & -0.024 & 0.830 & 0.2 \\
\hline \multicolumn{8}{|l|}{ Bombus pascuorum } \\
\hline Date of first queen (FQ) & 35 & 21 April b & 111.5 & 10.18 & -0.100 & 0.564 & 1.0 \\
\hline Date of first worker (FW) & 30 & 19 May b & 139.4 & 13.15 & -0.009 & 0.976 & $<0.1$ \\
\hline Duration: FQ to FW (days) dFW & 30 & - & $28.4 \mathrm{~b}$ & 13.45 & 0.259 & 0.371 & 2.9 \\
\hline Date of first male (FM) & 30 & 11 July a & 191.9 & 14.65 & -0.108 & 0.733 & 0.4 \\
\hline Beginning of main flight (BMF) & 34 & 28 July b & 209.3 & 8.71 & -0.339 & 0.021 & 15.4 \\
\hline End of main flight (EMF) & 34 & 17 August c & 229.5 & 5.79 & -0.371 & $<0.001$ & 41.9 \\
\hline Main flight: mid-date (MFM) & 34 & 8 August c & 219.6 & 6.62 & -0.349 & 0.001 & 28.4 \\
\hline Duration of main flight (days) (dMF) & 34 & - & $20.2 \mathrm{~b}, \mathrm{c}$ & 6.36 & -0.032 & 0.775 & 0.3 \\
\hline \multicolumn{8}{|l|}{ Bombus hortorum } \\
\hline Date of first queen (FQ) & 34 & 24 April a & 113.8 & 10.56 & -0.372 & 0.038 & 12.8 \\
\hline Date of first worker (FW) & 21 & 24 May b & 144.0 & 10.91 & 0.593 & 0.037 & 21.0 \\
\hline Duration: FQ to FW (days) dFW & 21 & - & $29.1 \mathrm{~b}$ & 13.05 & 1.177 & $<0.001$ & 57.8 \\
\hline Date of first male (FM) & 26 & 27 June $b$ & 177.8 & 14.68 & -0.062 & 0.850 & 0.2 \\
\hline Beginning of main flight (BMF) & 28 & 30 June c & 180.7 & 12.66 & -0.162 & 0.502 & 1.8 \\
\hline End of main flight (EMF) & 33 & 10 August $d$ & 221.8 & 9.49 & -0.543 & 0.001 & 32.6 \\
\hline Main flight: mid-date (MFM) & 28 & 20 July d & 201.0 & 8.38 & -0.299 & 0.053 & 13.6 \\
\hline Duration of main flight (days) (dMF) & 28 & - & $40.0 \mathrm{a}$ & 13.93 & -0.273 & 0.300 & 4.1 \\
\hline
\end{tabular}

Means are given as both date and day of the year together with their standard deviation (SD). The trend, significance $(p)$ and $\%$ variation explained $\left(R^{2}\right)$ are derived from regression of the variables on year. Significant trend results are shown in italics. Species means for each variable were compared using ANOVA (see text for details); means for the same variable not sharing the same lowercase letter(s) are significantly different $(p<0.05$, Tukey's tests)

$N$, the number of years of records 

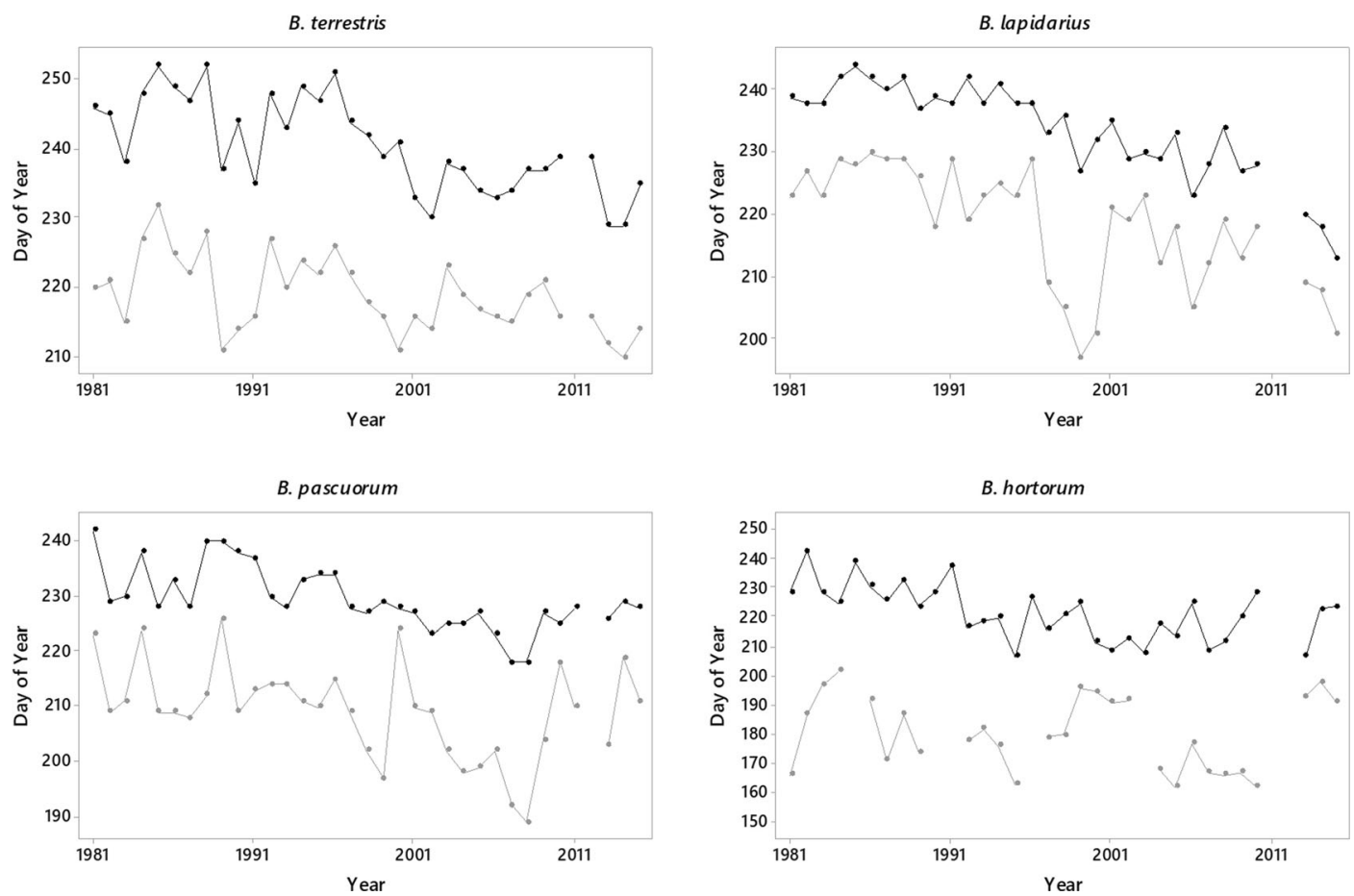

Figure 1. Change in the main flight period, shown as days of the year, for Bombus terrestris, Bombus lapidarius, Bombus pascuorum and Bombus hortorum. Grey and black lines show the beginning and end of the main flight period, respectively. Please note difference in y-scales but that all divisions are in 10-day intervals.

associated with increasing temperature. For the three other Bombus species, earlier flight dates were associated with warmer summers.

Whilst there appeared to be differences between species in their responses to temperature, including via effects on queen emergence, none of these differences achieved significance in a pooled regression.

\section{DISCUSSION}

To the best of our knowledge, long-term bumblebee phenology derived from field observations identified to species level has not previously been studied. Some long-term studies have been carried out based on museum specimens (Bartomeus et al. 2011) and where bumblebees have been bulked as

Table II. Summary of ANOVA comparing species means

\begin{tabular}{lllll}
\hline Variable & $d f_{1}$ & $d f_{2}$ & $F$ value & $p$ value \\
\hline Date of first queen (FQ) & 3 & 99 & 7.76 & $<0.001$ \\
Date of first worker (FW) & 3 & 78 & 9.74 & $<0.001$ \\
Duration: FQ to FW (days) dFW & 3 & 78 & 20.34 & $<0.001$ \\
Date of first male (FM) & 3 & 83 & 12.62 & $<0.001$ \\
Beginning of main flight (BMF) & 3 & 91 & 116.46 & $<0.001$ \\
End of main flight (EMF) & 3 & 96 & 68.11 & $<0.001$ \\
Main flight: mid-date (MFM) & 3 & 91 & 125.41 & $<0.001$ \\
Duration of main flight (days) (dMF) & 3 & 91 & 51.11 & $<0.001$ \\
\hline
\end{tabular}


Table III. A summary of mean values of and trends in monthly mean temperature and monthly precipitation in the Kujawy region of Poland during 1981-2015

\begin{tabular}{|c|c|c|c|c|c|c|c|c|}
\hline & \multicolumn{4}{|c|}{ Temperature $\left({ }^{\circ} \mathrm{C}\right)$} & \multicolumn{4}{|c|}{ Precipitation (mm) } \\
\hline & Mean & Trend & $p$ & $R^{2}(\%)$ & Mean & Trend & $p$ & $R^{2}(\%)$ \\
\hline $\mathrm{J}$ & -1.0 & 0.0134 & 0.813 & 0.2 & 29.0 & 0.342 & 0.111 & 7.5 \\
\hline $\mathrm{F}$ & 0.0 & 0.0438 & 0.433 & 1.9 & 23.3 & 0.118 & 0.464 & 1.6 \\
\hline M & 4.0 & 0.0112 & 0.763 & 0.3 & 29.6 & 0.071 & 0.727 & 0.4 \\
\hline A & 8.5 & 0.0599 & 0.006 & 20.8 & 28.3 & 0.052 & 0.805 & 0.2 \\
\hline M & 13.9 & -0.0002 & 0.991 & 0.0 & 52.5 & 0.570 & 0.084 & 8.8 \\
\hline $\mathrm{J}$ & 16.3 & 0.0445 & 0.012 & 17.8 & 66.3 & -0.204 & 0.619 & 0.8 \\
\hline $\mathrm{J}$ & 18.8 & 0.0579 & 0.020 & 15.3 & 76.7 & 0.765 & 0.183 & 5.3 \\
\hline A & 18.4 & 0.0428 & 0.023 & 14.6 & 58.5 & 0.102 & 0.819 & 0.2 \\
\hline $\mathrm{S}$ & 13.8 & 0.0226 & 0.322 & 3.0 & 43.3 & 0.040 & 0.902 & 0.1 \\
\hline $\mathrm{O}$ & 9.2 & -0.0060 & 0.821 & 0.2 & 31.0 & 0.098 & 0.729 & 0.4 \\
\hline $\mathrm{N}$ & 4.0 & 0.0712 & 0.028 & 13.8 & 34.4 & 0.051 & 0.839 & 0.1 \\
\hline D & 0.4 & 0.0349 & 0.406 & 2.1 & 33.2 & -0.215 & 0.391 & 2.2 \\
\hline
\end{tabular}

The trend, significance $(p)$ and \% variation explained $\left(R^{2}\right)$ are derived from regression of the variables on year. Significant trend results are shown in italics

Bombus spp. (Ovaskainen et al. 2013; Kudo and Cooper 2019). There have also been studies based on a limited number of field seasons (e.g. Goodwin 1995; Kudo and Ida 2013; Pyke et al. 2016) or along latitudinal or altitudinal gradients. We show in this paper that all aspects of the phenology of Bombus bumblebees differ between species. For example, B. terrestris had the earliest mean first date for queens, but the latest mean date for the end of main flight period. In contrast, $B$. hortorum had the latest mean first date for queens and the earliest end of main flight period. The species order of queen emergence was consistent with earlier studies from the UK which also reported differences in other aspects of species phenology (Alford 1969; Goodwin 1995). In the years 1981-2015, the main flight periods and some other aspects of the phenology of the dominant bumblebee species in Central Europe (B. terrestris, B. lapidarius, B. pascuorum and $B$. hortorum ) have advanced. This is in agreement with some of the bumblebee studies mentioned above and with predictions suggested by recent rapid climate change for many other organisms (reviews in: Hughes 2000; Sparks and Menzel 2002; Walther et al. 2002; Parmesan and Yohe 2003; Voigt et al. 2003; Badeck et al. 2004) including different groups of insects (Parmesan et al. 1999; Hickling et al. 2005; Tryjanowski et al. 2010; Rasmont et al. 2015). Our study revealed a generally consistent advance in the main flight period of the four studied bumblebee species apparently driven, at least partly, by temperature. However, there was some suggestion that the advance in the mid-date of the main flight period was greater for B. lapidarius than for the other species. There was also evidence of differences in trends in the date of the first worker. It should be noted that given the large number of analyses and large number of potential explanatory variables some significant relationships may have been included by chance alone.

Temperature effects dominated the phenology of the main flight period and give considerable support to findings of earlier flight in warmer years. However, despite apparent differences between species, formal comparisons did not reveal any statistically significant differences in temperature responses. This may be because, despite the series length, we still have only limited numbers of years of observation, and because of the high variability in the phenology of these species. Further data, or data obtained from controlled 
Table IV. Summary of stepwise regression models of bumblebee phenology in the Kujawy region of Poland during 1981-2015 in relation to the date of the first queen, antecedent monthly mean temperatures and antecedent total monthly precipitations

\begin{tabular}{|c|c|c|c|c|c|c|}
\hline & Candidates & Queen & Temperature & Precipitation & $R^{2}(\%)$ & Overall $p$ \\
\hline \multicolumn{7}{|c|}{ Bombus terrestris } \\
\hline $\mathrm{FQ}$ & FMA & & $\begin{array}{l}\text { Mar }-1.64 \pm 0.62 \\
\text { Apr } 0.27 \pm 0.11\end{array}$ & & 27.0 & 0.008 \\
\hline FW & QAMJ & $0.71 \pm 0.25$ & May $4.15 \pm 1.69$ & Apr $0.36 \pm 0.18$ & 42.5 & 0.002 \\
\hline $\mathrm{dFW}$ & QAMJ & & May $3.21 \pm 1.64$ & & 12.0 & 0.061 \\
\hline FM & QMJJ & & $\begin{array}{l}\text { May } 7.64 \pm 2.44 \\
\text { Jun }-5.82 \pm 2.92\end{array}$ & May $0.29 \pm 0.16$ & 33.7 & 0.012 \\
\hline BMF & QJJA & $0.28 \pm 0.10$ & $\mathrm{Jul}-1.16 \pm 0.56$ & & 26.0 & 0.009 \\
\hline EMF & QJJA & $0.22 \pm 0.12$ & $\mathrm{Jul}-2.18 \pm 0.68$ & & 27.6 & 0.007 \\
\hline MFM & QJJA & $0.25 \pm 0.10$ & $\mathrm{Jul}-1.60 \pm 0.59$ & & 26.7 & 0.008 \\
\hline $\mathrm{dMF}$ & QJJA & & $\mathrm{Jul}-1.08 \pm 0.41$ & & 17.8 & 0.013 \\
\hline \multicolumn{7}{|c|}{ Bombus lapidarius } \\
\hline FQ & FMA & & Mar $-1.90 \pm 0.77$ & & 15.9 & 0.019 \\
\hline FW & QAM & $0.84 \pm 0.15$ & & & 54.1 & $<0.001$ \\
\hline $\mathrm{dFW}$ & QAM & & & & No model & \\
\hline $\mathrm{FM}$ & QMJJ & $0.44 \pm 0.17$ & & & 18.8 & 0.017 \\
\hline BMF & QJJA & & Jun $-3.94 \pm 1.43$ & & 19.7 & 0.010 \\
\hline EMF & QJJA & & $\begin{array}{l}\text { Jun }-1.97 \pm 1.16 \\
\text { Jul }-1.72 \pm 0.80\end{array}$ & & 24.9 & 0.014 \\
\hline MFM & QJJA & & Jun $-3.28 \pm 1.23$ & & 18.8 & 0.012 \\
\hline $\mathrm{dMF}$ & QJJA & & & & No model & \\
\hline \multicolumn{7}{|c|}{ Bombus pascuorum } \\
\hline $\mathrm{FQ}$ & FMA & & Apr $-2.56 \pm 1.24$ & & 11.4 & 0.047 \\
\hline FW & QAM & $0.47 \pm 0.21$ & & & 14.7 & 0.036 \\
\hline dFW & QAM & $-0.53 \pm 0.21$ & & & 18.5 & 0.018 \\
\hline $\mathrm{FM}$ & QMJJ & & & & No model & \\
\hline $\mathrm{BMF}$ & QMJJ & & Jun $-2.73 \pm 1.32$ & & 11.8 & 0.047 \\
\hline EMF & QJJA & & Jun $-2.56 \pm 0.82$ & & 23.5 & 0.004 \\
\hline MFM & QJJA & & Jun $-2.62 \pm 0.96$ & & 18.8 & 0.010 \\
\hline $\mathrm{dMF}$ & QJJA & & & & No model & \\
\hline \multicolumn{7}{|c|}{ Bombus hortorum } \\
\hline FQ & FMA & & & & No model & \\
\hline FW & QAM & $0.41 \pm 0.19$ & Apr $3.90 \pm 1.56$ & & 33.2 & 0.026 \\
\hline $\mathrm{dFW}$ & QAM & $-0.59 \pm 0.19$ & Apr $3.90 \pm 1.56$ & & 53.3 & 0.001 \\
\hline $\mathrm{FM}$ & QAMJ & & May $4.16 \pm 2.38$ & & 11.3 & 0.093 \\
\hline BMF & QAMJ & & May $4.25 \pm 2.00$ & & 14.8 & 0.043 \\
\hline EMF & QJJA & & Jun $-3.61 \pm 1.38$ & $\mathrm{Jul}-0.09 \pm 0.04$ & 26.9 & 0.009 \\
\hline MFM & QMJJ & & & & No model & \\
\hline $\mathrm{dMF}$ & QJJA & & & & No model & \\
\hline
\end{tabular}

The second column indicates which variables were candidate variables in the stepwise regression. Variables: date of first queen (FQ), date of first worker (FW), date of first male (FM), beginning of main flight (BMF), end of main flight (EMF), main flight middate (MFM), duration of main flight (dMF; days). Coefficients $\pm \mathrm{SE}$ of selected variables are shown together with overall model $R^{2}$ and significance

$Q$, date of first queen (with other letters indicating the two or three sequential months of both temperature and precipitation) 

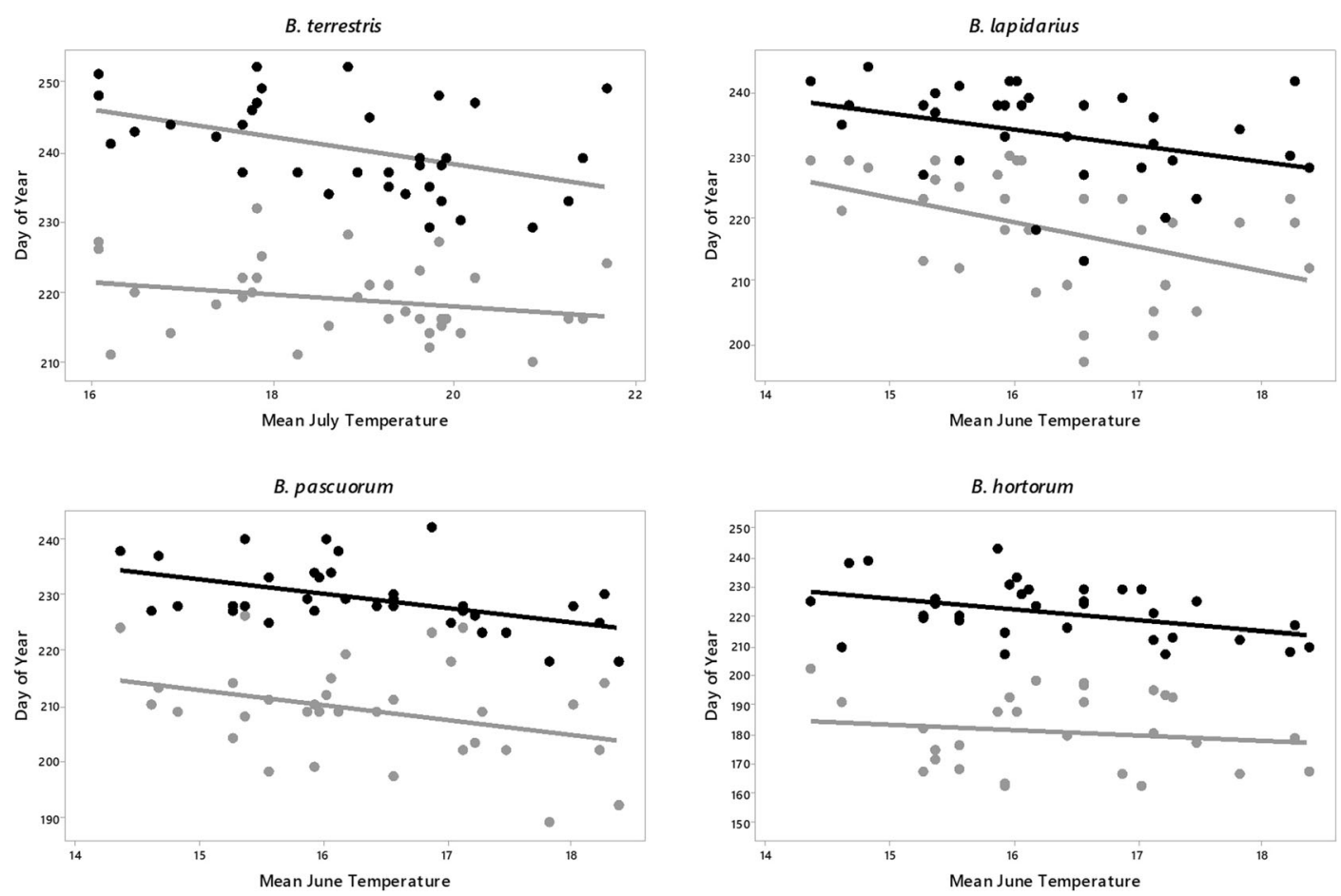

Figure 2. Relationship between the beginning (grey) and end (black) of the main flight period, shown as days of the year, for Bombus terrestris, Bombus lapidarius, Bombus pascuorum and Bombus hortorum and temperature. For illustration purposes, mean June temperature $\left({ }^{\circ} \mathrm{C}\right)$ is used, except for $B$. terrestris where mean July temperature $\left({ }^{\circ} \mathrm{C}\right)$ is presented. Regression lines superimposed. Please note difference in y-scales but that all divisions are in 10-day intervals.

experiments will be needed to provide a definitive answer to the question of whether species differences in temperature responses exist. Since the phenologies of the species can be markedly different, for example, some aspects of B. hortorum phenology were a month earlier than the other studied species, it was anticipated that the climatic drivers of their phenology would differ.

Further evidence for the variability in the data can be inferred from the fact that the relationships with weather conditions, especially temperature, appear less clear than those found for similar insects, such as the honey bee Apis mellifera L. (Gordo and Sanz 2006). We believe that the phenology of bumblebees may be less sensitive to temperature than some other invertebrates. Suggestions of species-specific responses among Bombus to increasing temperatures are particularly important given that some previous authors have bulked phenology from different Bombus species. It should be noted that a slightly lower abundance of $B$. hortorum in the study area resulted in fewer valid years of phenology for this species and potentially less reliable climate relationships.

Given what we know on the phenology of other insects and of flowering plants we would expect that the phenology of bumblebees would also advance, especially given the significant increases in April, June, July and August mean temperatures during the study period. Our data were most consistent in terms of advances in multiple aspects of the main flight period. First emergence of queens showed a temperature response, except for $B$. hortorum. This is consistent with the critical temperature thresholds for queen emergence indicated by other authors (e.g. Alford 1969; Goodwin 1995; Kudo and Cooper 2019). Later aspects of bumblebee phenology were often associated with the dates of first queen. This aspect may be direct, 
via development rates of the colony after queen emergence, although it would be unwise to rule out the possibility of temperature effects for which first queen date might simply be a surrogate. For three of the species, all three measures of the main flight period (beginning, end, mid-date) advanced significantly, but for B. hortorum, only the end of the main flight advanced significantly. These aspects of bumblebee phenology were associated with the significant increases in summer temperatures mentioned earlier. These temperature effects may be direct, affecting the physiology and development rates of the bees themselves, or indirect via advanced flowering encouraging earlier activity. Bock et al. (2014) reported an overall shorter flowering duration. If this occurred also in Poland, then it might encourage a shorter main flight period in bumblebees. Whilst all main flight durations had a negative trend (i.e. towards becoming shorter) only one of these was significant.

Colony initiation after hibernation is known to be faster under higher mean air temperature (Pawlikowski 1984; Alford 2011). In spring, during April-May, all bumblebees in the Central European Plain start to develop colonies in nests (Pawlikowski 1996). The effectiveness of this stage of the life cycle is not so much dependent on temperature as on precipitation, although precipitation featured only peripherally in our models. It has been found that the efficiency of colony development is very susceptible to fungal pathogens (Goulson 2010; Alford 2011), which increase under high humidity associated with heavy rainfall. Both drought and excessive rainfall were reported by Goodwin (1995) to adversely affect bumblebee abundance. A delay in phenology associated with higher precipitation was detected for some aspects of $B$. terrestris .

As a dominant group of species in an agricultural landscape, bumblebees function as a polyphagous community which increases its own activity in a floristically diverse environment (Goulson 2010; Alford 2011). Therefore, they may switch to different food sources (Heinrich 1993) depending on prevailing temperature. However, the advances in some aspects of bumblebee phenology may cause potential conflicts with early season adverse weather conditions and need to be considered.
Other studies have reported temperature response in the duration of the main flight of Vespinae wasps (Tryjanowski et al. 2010), insect migration timing (e.g. Kullberg 1995), population structure (e.g. Fordham et al. 1991), larval development rates (Archer 1998) and changes in distribution (e.g. Spradbery and Maywald 1992).

Some aspects of the phenology of the bumblebees studied, especially the main flight period, clearly changed and were consistent with increased temperatures in the study area. We have not been able to fully explain the magnitude of change and suggest that further study, particularly experimental, would be advantageous. Variables such as frost and rainfall frequency, sunshine, drought or maximum temperature may be more important than those that we considered here. Furthermore, it may be that the bumblebees are having to 'catch-up' with earlier advances in the phenology of flowering plants and that their response to temperature is partly indirect and delayed. Climate change is likely to affect many aspects of the life cycles of bumblebees and, as a consequence, the resulting potential conflicts between them need to be investigated.

\section{ACKNOWLEDGEMENTS}

We are grateful to K. Kujawa for assistance and P. Tryjanowski for helpful comments. The comments of two anonymous reviewers helped to improve the manuscript.

\section{AUTHORS CONTRIBUTIONS}

$\mathrm{TP}$ and KP conceived this research and undertook field recording; PO and LR prepared all materials for the manuscript; TP generated the first draft of the manuscript, subsequently revised and edited by THS; RJ and THS undertook analysis of the data. All authors read and approved the final manuscript.

\section{COMPLIANCE WITH ETHICAL STANDARDS}

Conflict of interest The authors declare that they have no conflict of interest. 
Data availability statement The datasets analysed during the current study are available from the corresponding author on reasonable request.

\section{OPEN ACCESS}

This article is licensed under a Creative Commons Attribution 4.0 International License, which permits use, sharing, adaptation, distribution and reproduction in any medium or format, as long as you give appropriate credit to the original author(s) and the source, provide a link to the Creative Commons licence, and indicate if changes were made. The images or other third party material in this article are included in the article's Creative Commons licence, unless indicated otherwise in a credit line to the material. If material is not included in the article's Creative Commons licence and your intended use is not permitted by statutory regulation or exceeds the permitted use, you will need to obtain permission directly from the copyright holder. To view a copy of this licence, visit http://creativecommons. org/licenses/by/4.0/.

La hausse des températures fait avancer la principale période de vol des bourdons Bombus dans les paysages agricoles de la plaine d'Europe centrale.

bourdon / Bombus / climat / agriculture / phénologie.

Steigende Temperaturen begünstigen die Hauptflugzeit der Bombus-Hummeln in der Agrarlandschaft der mitteleuropäischen Ebene.

\section{Hummel / Bombus / Klima / Landwirtschaft / Phänologie.}

\section{REFERENCES}

Alford D.V. (1969) A study of the hibernation of bumblebees (Hymenoptera: Bombidae) in southern England. J. Anim. Ecol. 38, 149-170

Alford D.V. (2011) Bumblebees. Northern Bee Books, Hebden Bridge

Archer M.E. (1998) A lifetime with wasps (Hymenoptera: Vespidae). Naturalist 123, 3-14

Badeck F.W., Bondeau A., Bottcher K., Doctor D., Lucht W. (2004) Responses of spring phenology to climate change. New Phytol. 162, 295-309
Bale J.S., Masters G.J., Hodkinson I.D., Awmack C., Bezemer T.M. et al (2002) Herbivory in global climate change research: direct effects of rising temperature on insect herbivores. Glob. Change Biol. 8, 1-16

Bartomeus I., Ascher J.S., Wagner D., Danforth B.N., Colla S., Kornbluth S., Winfree R. (2011) Climate-associated phenological advances in bee pollinators and beepollinated plants. PNAS 108, 20645-20649

Biliński M. (1997) Gniazda trzmieli w naturze (bumblebee nests occurring in nature). In Cierzniak T. (Ed.), Postępy apidologii w Polsce (pp. 119-134). Wyższa Szkoła Pedagog, Bydgoszcz (in Polish with an English summary)

Bock A., Sparks T.H., Estrella N., Jee N., Casebow A., Schunk C., Leuchner M., Menzel A. (2014) Changes in first flowering dates and flowering duration of 232 plant species on the island of Guernsey. Glob. Change Biol. 20, 3508-3519

Dell D., Sparks T.H., Dennis R.L.H. (2005) Climate change and the effect of increasing spring temperatures on emergence dates of the butterfly Apatura iris (Lepidoptera: Nymphalidae). Eur. J. Entomol. 102 , 161-167

Fordham R.A., Craven A.J., Minot E.O. (1991) Phenology and population structure of annual nests of the German wasp Vespula germanica (Fab.) in Manawatu, New Zealand, with particular reference to late summer and autumn. N.Z. J. Zool. 18, 127-137

Goodwin S.G. (1995) Seasonal phenology and abundance of early-, mid- and long-season bumble bees in southern England, 1985-1989. J. Apic. Res. 34, 79-87

Gordo O., Sanz J.J. (2006) Temporal trends in phenology of the honey bee Apis mellifera (L.) and the small white Pieris rape (L.) in the Iberian Peninsula (1952-2004). Ecol. Entomol. 31 , 261-268

Goulson D. (2010) Bumblebees: behaviour, ecology, and conservation. Oxford University Press, Oxford

Harrington R., Clark S.J., Welham S.J., Verrier P.J., Denholm C.H., Hulle M., Maurice D., Rounsevell M.D., Cocu N., E.U. Examine Consortium (2007) Environmental change and the phenology of European aphids. Glob. Change Biol. 13, 1550-1564

Harris I., Jones P., Osborn T., Lister D. (2014) Updated highresolution grids of monthly climatic observations - the CRU TS3.10 Dataset. Int. J. Climatol. 34, 623-642

Heinrich B. (1993) The hot-blooded insects - strategies and mechanisms of thermoregulation. Springer Verlag, Berlin-Budapest

Hickling R., Roy D.B., Hill J.K., Thomas C.D. (2005) A northward shift of range margins in British Odonata. Glob. Change Biol. 11, 502-506

Hughes L. (2000) Biological consequences of global warming. Is the signal already apparent? Trends Ecol. Evol. 15, 56-61

Konvicka M., Maradowa M., Benes J., Fric Z., Kepka P. (2003) Uphill shifts in distribution of butterflies in the Czech Republic: effects of changing climate detected on a regional scale. Glob. Ecol. Biogeogr. 12 , 403-410 
Kudo, G., Cooper, E.J. (2019) When spring ephemerals fail to meet pollinators: mechanism of phenological mismatch and its impact on plant reproduction Proceedings of the Royal Society B 286, 20190573

Kudo G., Ida T.Y. (2013) Early onset of spring increases the phenological mismatch between plants and pollinators. Ecology 94, 2311-2320

Kullberg J. (1995) Migration of hornet (Vespa crabro L.) in southwestern archipelago in Finland in 1992. Sahlbergia 2, 112

Le Conte Y., Navajas M. (2008) Climate change: impact on honey bee populations and diseases. Rev. Sci. Tech. Int. Epiz. 2, 499-510

Martinet B., Rasmont P., Cederberg B., Evrard D., Ødegaard F., Paukkunen J., Lecocq T. (2015) Forward to the north: two Euro-Mediterranean bumblebee species now cross the Arctic Circle. Ann. Soc. Entomol. Fr. 51, 303-309

Ovaskainen O., Skorokhodova S., Yakovleva M., Sukhov A., Kutenkov A., Kutenkova N., Shcherbakov A., Meyke E., del Mar Delgado M. (2013) Phenological response to climate change. PNAS $110,13434-13439$

Parmesan G., Yohe G. (2003) A globally coherent fingerprint of climate change impacts across natural systems. Nature 421 , 37-42

Parmesan C., Ryrholm N., Stefanescu C., Hill J.K., Thomas C.D. (1999) Poleward shifts in geographical ranges of butterfly species associated with regional warming. Nature 399, 579-583

Pawlikowski T. (1984) Unusual instance of hibernation by bumblebee Bombus terrestris (L.). Przegląd Zoologiczny 28, 233-235

Pawlikowski T. (1996) Bees-Apidae. Turpress, Toruń

Pawlikowski T. (2008) A distribution Atlas of bumblebees in Poland (Hymenoptera: Apidae: Bombini). UMK, Toruń

Pawlikowski T., Barczak T., Bennewicz J. (2008) Bees (Hymenoptera: Apiformes) of the agricultural areas in the lower Vistula valley. J. Apicult. Sci. 52 , 1-13

Pyke G.H., Thomson J.D., Inouye D.W., Miller T.J. (2016) Effects of climate change on phenologies and distributions of bumble bees and the plants they visit. Ecosphere 7, e01267

Rasmont P., Coppée A., Michez D., De Meulemeester T. (2008) An overview of the Bombus terrestris (L.
1758) subspecies (Hymenoptera: Apidae). Ann. Soc. Entomol. Fr. 44, 243-250

Rasmont P., Franzen M., Lecocq T., Harpke A., Roberts S.P.M. et al (2015) Climatic risk and distribution Atlas of European bumblebees. Pensoft, Sofia

Sparks T.H., Menzel A. (2002) Observed changes in seasons, an overview. Int. J. Climatol. 22 , 1715-1722

Sparks T.H., Dennis R.L.H., Croxton P.J., Cade M. (2007) Increased migration of Lepidoptera linked to climate change. Eur. J. Entomol. 104, 139-143

Spradbery J.P., Maywald G.F. (1992) The distribution of the European or German wasp, Vespula germanica (F.) (Hymenoptera, Vespidae), in Australia-past, present and future. Austral. J. Zool. 40, 495-510

Tryjanowski P., Pawlikowski T., Pawlikowski K., Banaszak-Cibicka W., Sparks T.H. (2010) Does climate influence phenological trends in social wasps (Hymenoptera: Vespinae) in Poland? Eur. J. Entomol. 107, 203-208

Velthuis H.H.W. (2002) The historical background of the domestication of the bumble-bee Bombus terrestris and its introduction in agriculture. In Kevan P., Imperatriz Fonseca V.L. (Eds.), Pollinating bees - the conservation link between agriculture and nature (pp. 177-184). Ministry of Environment, Brasilia

Voigt W., Perner J., Davis A.J., Eggers T., Schumacher J. et al (2003) Trophic levels are differentially sensitive to climate. Ecology 84, 2444-2453

Walther G.R., Post E., Convey P., Menzel A., Parmesan C., Beebee T.J.C., Fromentin J.M., Hogh-Guldberg O., Bairlein F. (2002) Ecological responses to recent climate change. Nature 416, 389-395

Warren M.S., Hill J.K., Thomas J.A., Asher J., Fox R., Huntley B., Roy D.B., Telfer M.G., Jeffcoate S., Harding P., Jeffcoate G., Willis S.G., Greatorex-Davies J.N., Moss D., Thomas C.D. (2001) Rapid responses of British butterflies to opposing forces of climate and habitat change. Nature 414, 65-69

Williams, P. (2000) Bombus bumblebees of the world [Online] http://www.nhm.ac.uk/researchcuration/research/projects/bombus. Accessed 28 Dec 2018)

Publisher's note Springer Nature remains neutral with regard to jurisdictional claims in published maps and institutional affiliations. 